\title{
Assessments on Sustainability Potential by Upgrade of Existing Heritage Buildings: a case study of Liyuan Courtyard in Qingdao, China
}

\section{Yi Huang ( $\sim 75593861 @ q q . c o m$ )}

Qingdao Agricultural University, China https://orcid.org/0000-0003-2731-5240

\section{Yufan Xiao}

Qingdao University of Technology

Fan Yu

Harbin Institute of Technology

Original article

Keywords: Sustainability, Renovation, Energy Saving, heritage buildings

Posted Date: September 28th, 2020

DOI: https://doi.org/10.21203/rs.3.rs-76675/v1

License: (c) (i) This work is licensed under a Creative Commons Attribution 4.0 International License.

Read Full License 


\section{Abstract}

Background: The existing heritage buildings are considered as symbols of the original spirit of a city, which also contains vitality and resilience through centuries. In Qingdao, the Liyuan courtyard styles are still existed as a very regional and representative colonial residential architecture form in the urban development history from 1900s in this city.

Method: The research here made the hypotheses of the heritage buildings can regain its authentic appearance while achieve energy efficiency in building performance through optimization and renovation strategies. The sustainability potentials assessment is discussed and evaluated with field investigation in a Liyuan building case study by on-site observation and building performance simulation analysis of two renovation options.

Result and Discussion: One model with façade supplemented in the insulation layers in the envelope walls and another model with further upgrade with consideration of recycling materials mixed were discussed and estimated with building performance simulation method. Both scenarios improved the energy efficiency, while the advanced model could achieve better result in the building energy behavior dramatically.

Conclusion: This research paper verified the hypotheses of sustainability embodied in Liyuan buildings. It also confirmed the vitality and resilience could be regained through history with considerable and reasonable guideline in strategy together with personal alternatives. Technologies innovation helps to improve their energy performance by reducing consumption or self-supplying on the existing buildings renovation actions. Every specific choices of renovation action could achieve low energy goals and impose optional positive effects on the behavior of the living comfort preference. Multicriteria considerations might influence the balanced between different factors when making decisions in the heritage building restoration and it is expected to empower the fresh glory in the development of heritage building protection and restoration.

\section{Full Text}

This preprint is available for download as a PDF.

\section{Figures}



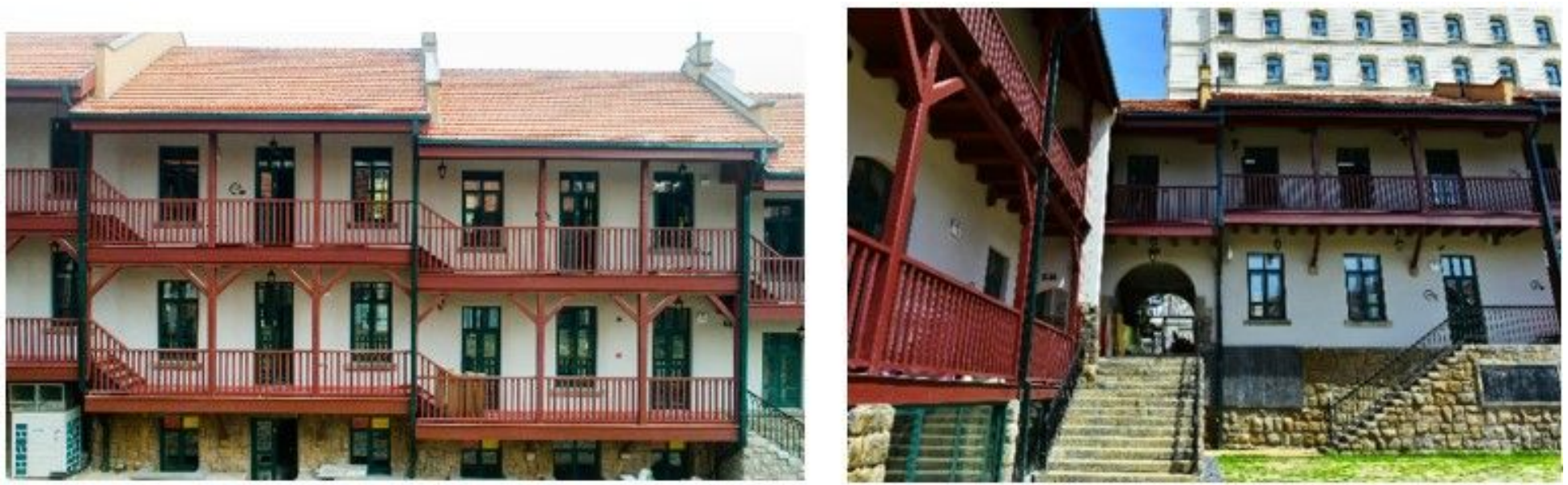

Figure 1

The appearance of the retrofit sample in one of the Liyuan courtyard buildings mainly focused on the outlooks.
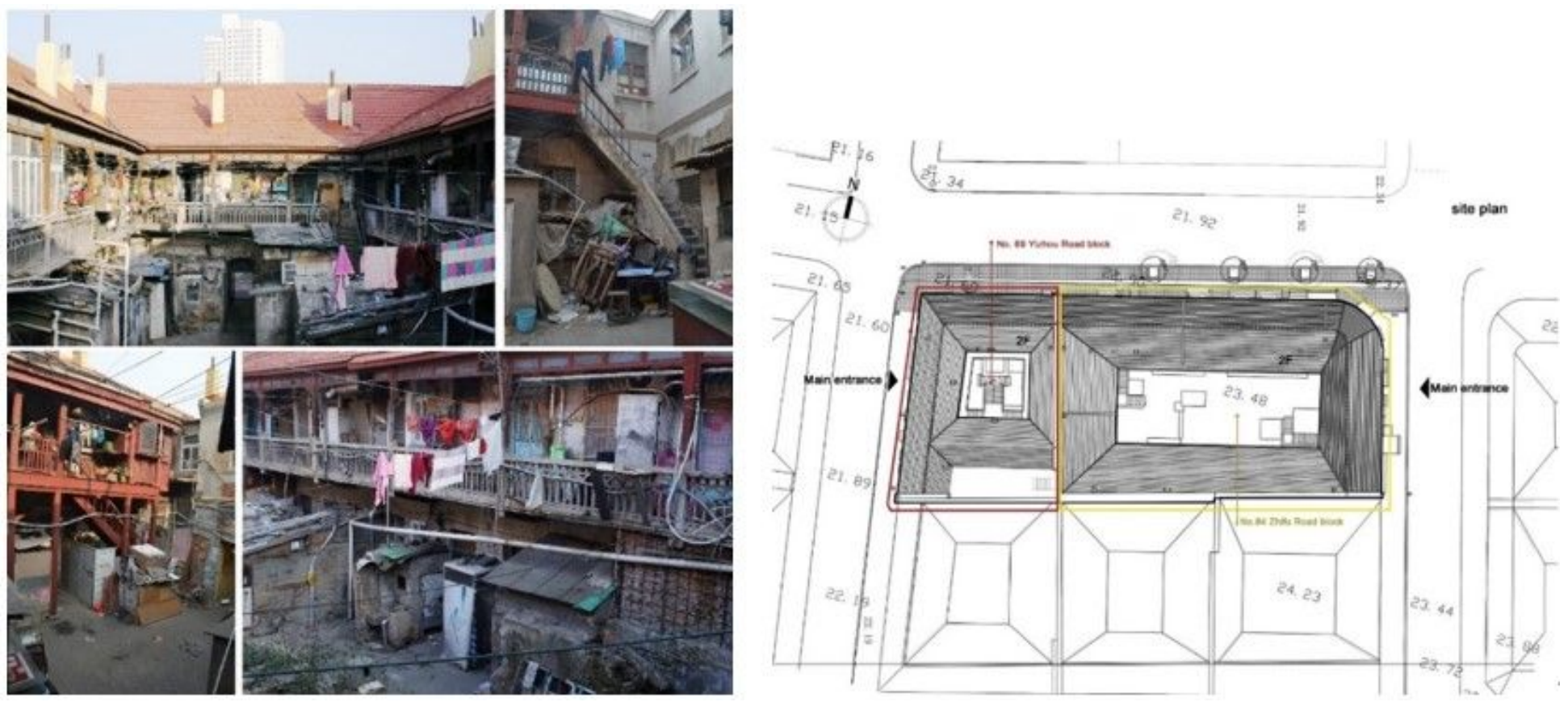

Figure 2

Some photograph record of the details in the courtyard (left) and initial sketch of the plan sight of the building 

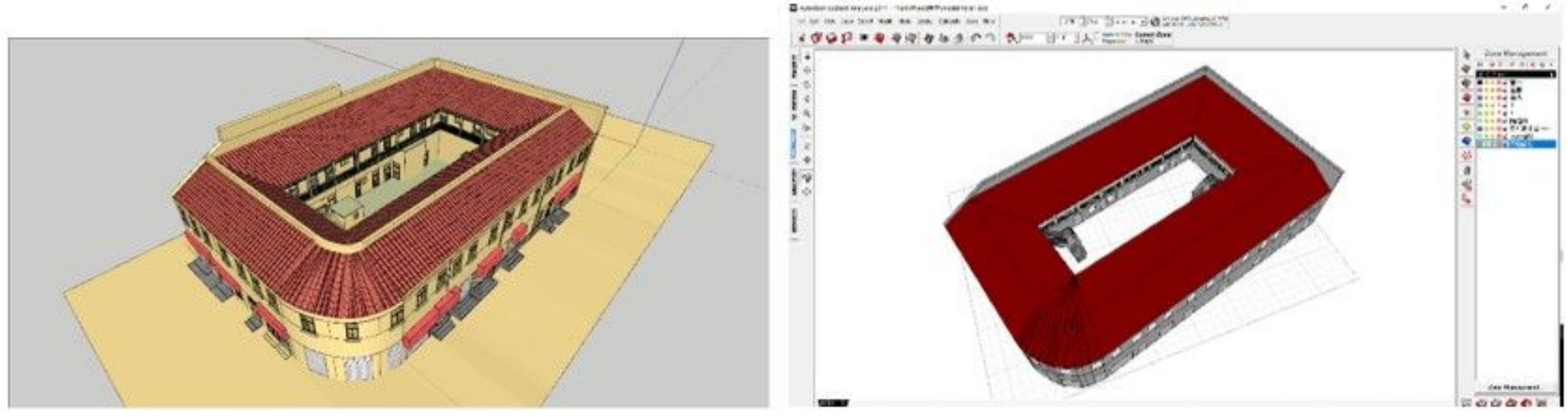

\section{Figure 3}

The parametric model through ICT software SketchUp software(left); the energy simulation software Ecotect (right).
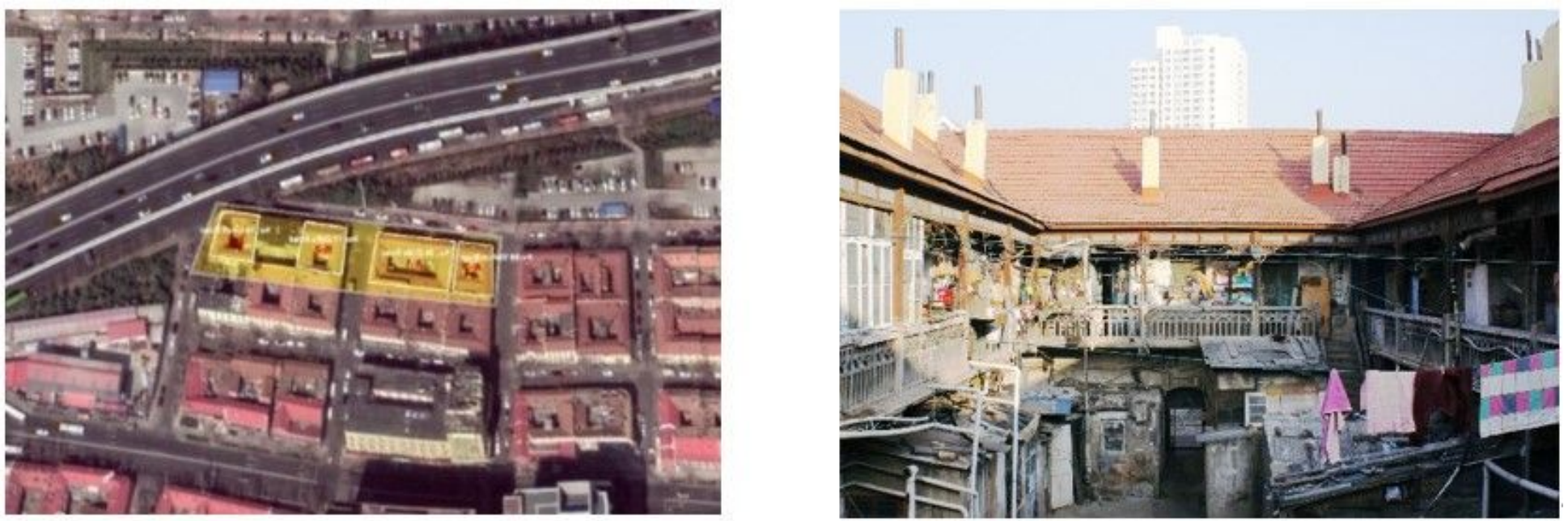

Figure 4

The satellite photo of the location information of the "Liyuan courtyard" ZF-84 case (left); the current situation pictures inside the courtyard (right). 


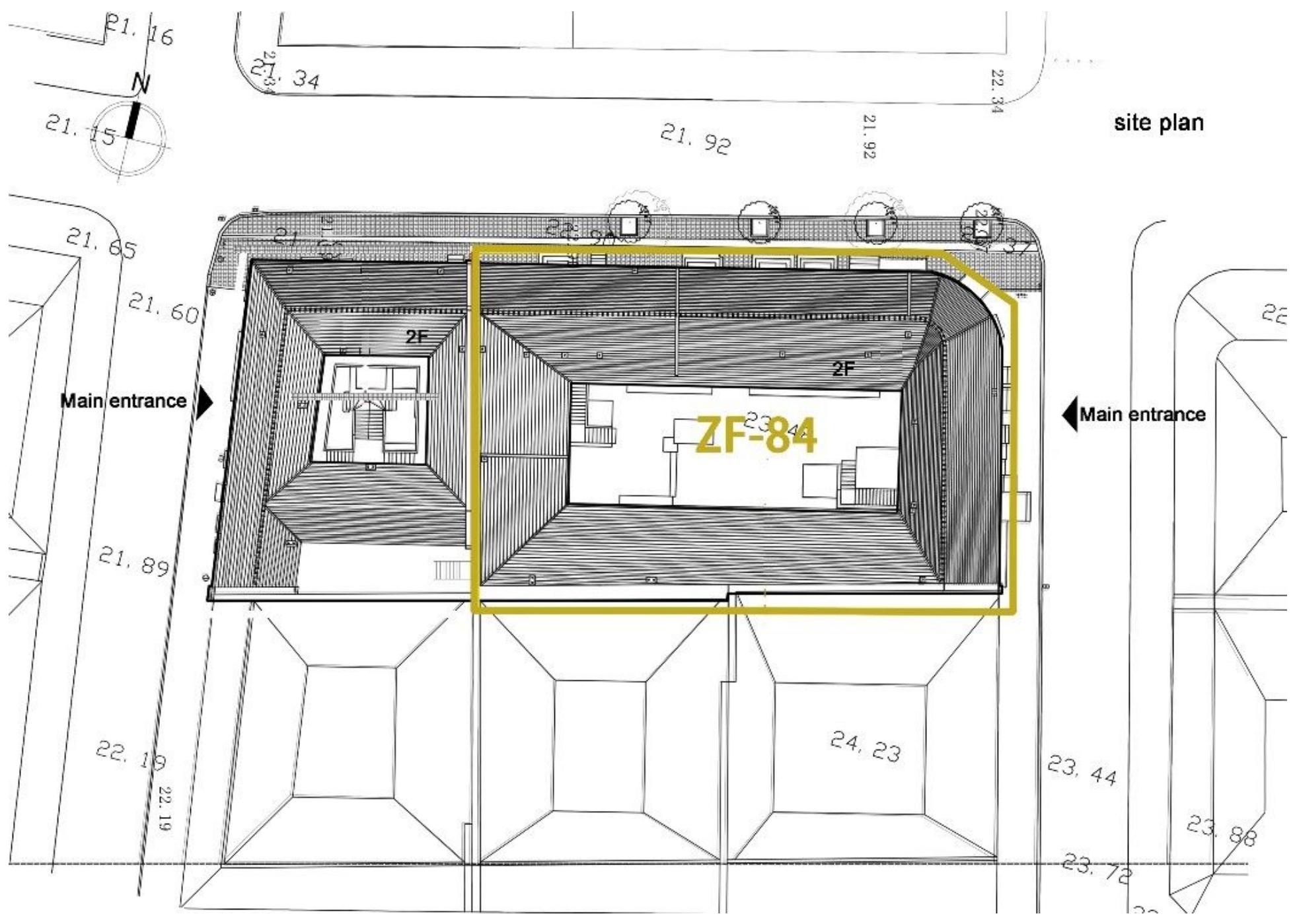

Figure 5

The constitution of the ZF-84 case study in the block area (the Yellow part). 